ORIGINAL ARTICLE

\title{
Neutrophil and monocyte adhesion molecules in bronchopulmonary dysplasia, and effects of corticosteroids
}

\author{
P Ballabh, M Simm, J Kumari, A N Krauss, A Jain, C Califano, M L Lesser, S Cunningham-Rundles
}

Arch Dis Child Fetal Neonatal Ed 2004;89:F76-F83

See end of article for authors' affiliations

Correspondence to:

Correspondence to:
Dr P Ballabh, Assistant

Professor, Division of

Neonatology, Department

of Pediatrics, NICU, 2nd

Floor, Main Building,

Westchester Medical

Center, Valhalla, NY

10595, USA;

Pballabh@msn.com

Accepted 11 March 2003

\begin{abstract}
Aims: To study a longitudinal change in the expression of adhesion molecules CD1 1b, CD18, and CD62L on neutrophils and monocytes in very low birth weight babies who develop respiratory distress syndrome, to compare these levels between bronchopulmonary dysplasia (BPD) and non-BPD infants, and to assess the effect of corticosteroid treatment on these adhesion molecules.

Methods: Of 40 eligible neonates, 11 neonates were oxygen dependent at 36 weeks (BPD 36 weeks), 16 infants were oxygen dependent at 28 days, but not at 36 weeks (BPD d28), and 13 infants did not develop BPD. Seventeen neonates received a six day course of steroid treatment. Expression of CD1 1b, CD18, and CD62L was measured on neutrophils and monocytes in arterial blood on days 1, 3, 7, 14, 21, and 28, and before and 2-3 days after initiation of dexamethasone treatment by flow cytometry.

Results: CD18 expression on neutrophils and monocytes and CD62L on neutrophils, measured as mean fluorescent intensity, was significantly decreased in BPD neonates compared to non-BPD neonates on days 1-28. Dexamethasone treatment significantly decreased CD11b, CD18, and CD62L expression on neutrophils, and CD1 $1 \mathrm{~b}$ and $\mathrm{CD} 18 \mathrm{~L}$ expression on monocytes.

Conclusions: Decreased CD18 expression on neutrophils and monocytes, and decreased CD62L expression on neutrophils, measured as mean fluorescent intensity during the first four weeks of life in micropremies may be risk factors and early predictors of BPD. Dexamethasone use was associated with decreased expression of CD1 1b, CD18, and CD62L.
\end{abstract}

B ronchopulmonary dysplasia (BPD) or chronic neonatal lung disease is a major complication of premature birth associated with barotrauma and high oxygen concentration that continues to affect the micropremies despite advances in clinical care. ${ }^{1-3}$ There is increasing evidence that inflammation is central to the development of BPD and leads to entry of inflammatory cells into the lung during postnatal ventilation, oxygen administration, and exposure to microbial antigen..$^{4-6}$ Neuropeptide release may also accelerate this process. Glucocorticoid therapy, specifically dexamethasone, opposes this process, reducing duration of oxygen dependence and incidence of BPD, but has adverse effects on growth and development. ${ }^{7-10}$ Thus, understanding the basic mechanisms of BPD is critical for early identification of neonatal risk and might also reveal key factors that could help form the basis of a rationale for dexamethasone treatment, and potentially lead to other new treatment strategies.

Neutrophil activation and transepithelial migration secondary to inflammation and independent of clinical sepsis has been implicated in respiratory distress syndrome (RDS) which precedes the development of BPD in this setting. ${ }^{11}$ The migration of neutrophils to the alveoli occurs in several variable steps involving transient adhesion and rolling, mediated by E-selectin, P-selectin, L-selectin, and intercellular adhesion molecule-1 (ICAM-1), followed by firm adhesion, and then transendothelial migration. ${ }^{12}$ Selectin deficient mice show impaired leucocyte recruitment. ${ }^{13}$ Increased levels of soluble E-selectin and ICAM-1 were observed in cord blood and serum of premature infants who subsequently developed BPD. ${ }^{14}$ CD62L, the leucocyte endothelial cellular adhesion molecule, and human analogue of the murine lymph node homing receptor is expressed on $\mathrm{T}$ cells, granulocytes, and monocytes.

Downregulation of CD62L on leucocytes is a possible mechanism of neutrophilia during inflammation. ${ }^{15}$ L-selectin is involved in leucocyte accumulation. ${ }^{16} \mathrm{CD} 18$, the $\beta_{2}$ integrin mediating the firm neutrophil adhesion to the endothelium has emerged as a critical adhesion molecule in inflammation. CDllb expression is increased in neonatal infection. ${ }^{17}$ Increased CDIlb/CD18 on neutrophils has been observed in tracheobronchial fluid of babies who developed BPD. ${ }^{18}$ Dexamethasone treatment appears to downregulate the expression of CD11/CD18 and upregulate CD62L in neutrophils, ${ }^{19}$ but decreased CD62L in BPD neonates after initiation of dexamethasone has been reported. ${ }^{20}$

In this investigation, we sought to define differences in CD62L, CD18, or CD1 lb expression in premature infants with RDS that might be linked to the development of BPD in the absence of clinical infection. Adhesion molecule expression on monocytes was examined as well since these cells are both recruited to inflamed sites and produce proinflammatory cytokines. ${ }^{21}$ Finally, we studied the effect of dexamethasone therapy on adhesion molecules during the postnatal period.

\section{PATIENTS AND METHODS \\ Patients}

The Committee on Human Rights in Research institutional review board at Weill Medical College of Cornell University (W-CUMC), New York approved this study. A written consent was obtained from parents of all participating newborns. We studied a sample of 51 infants admitted to the Neonatal Intensive Care Unit, W-CUMC from April 1999 to June 2000. Patients were essentially enrolled consecutively except for logistical reasons or when the mother did not consent. The infants were preterm with RDS, weighing less

\footnotetext{
Abbreviations: BPD, bronchopulmonary dysplasia; CPAP, continuous positive airway pressure; ICAM, intercellular adhesion molecule; RDS, respiratory distress syndrome
} 
than $1200 \mathrm{~g}$ and less than 30 weeks gestation. Babies were considered to have RDS if they required continuous positive airway pressure (CPAP) for more than one day, mechanical ventilation for more than one day, or supplemental oxygen for more than three days, with chest $x$ ray changes suggestive of RDS. Our practice is to use mechanical ventilation if the oxygen requirement is more than $40-50 \%$ for babies on CPAP of $5 \mathrm{~cm}$ water, or if there is a significant respiratory acidosis. All babies placed on ventilator received surfactant. Babies with culture proven sepsis in the first two weeks, major congenital anomalies, or death within a month were excluded. Eleven babies were excluded, seven for early death from respiratory failure, and four for early neonatal sepsis. All premature infants born following preterm labour received a sepsis work up at birth (including blood culture and complete blood cell count), and received antibiotics for 48 hours pending blood culture results.

\section{Study design}

Arterial blood samples were collected on eligible infants on postnatal days $1,3,7,14,21$, and 28, and before initiation, 2-3 days after, and 2-4 days after discontinuation of dexamethasone. Seventeen babies received dexamethasone treatment after 2 weeks of age for the purpose of weaning them from ventilator or oxygen support according to status at the discretion of their neonatologists. Participation in the study did not alter medical management of the infant. At this time we used dexamethasone in infants with evolving BPD after 2 weeks of postnatal age if the infant had an $\mathrm{FIO}_{2}$ requirement of $>40 \%$ and showed no likelihood of weaning over a two day period. Currently use of dexamethasone is more infrequent, and in much smaller doses and shorter duration $(0.125 \mathrm{mg} / \mathrm{kg}$ for three days) because of emerging concerns.

Blood samples were collected in sodium heparinised tubes and were studied freshly. Infants were followed until discharge and were classified into three groups:

- Non-BPD $(n=13)$ : no oxygen at day 28.

- BPD d28 ( $\mathrm{n}=16)$ : oxygen at day 28 and not at 36 weeks corrected gestational age, with radiographic changes consistent with BPD.

- BPD 36 weeks $(n=11)$ : these babies were oxygen dependent at day 28 and also at 36 weeks of corrected gestational age.

Chest $\mathrm{x}$ ray of all neonates at 25-30 days of age, who were oxygen dependent on day 28 , was reviewed by an experienced paediatric radiologist for the radiological signs of BPD. ${ }^{22}$ The radiologist was blinded to study groups.

\section{Dexamethasone therapy}

Seventeen patients were treated with dexamethasone for six days after 2 weeks of age. Thirteen neonates were started on corticosteroids during the third or fourth week, and four during the fifth or sixth week of life. The dose of dexamethasone was $0.5 \mathrm{mg} / \mathrm{kg} /$ day in two divided doses for two days, tapered to $0.25 \mathrm{mg} / \mathrm{kg} /$ day for the next two days, then $0.125 \mathrm{mg} / \mathrm{kg} / \mathrm{day}$ for the last two days. Blood samples were drawn before (pre-dex), after 2-3 days of initiation (ondex), and 2-4 days after discontinuation (off-dex) of dexamethasone. CD1 lb, CD18, and CD62L levels normalised with in 2-3 days of discontinuation of dexamethasone. Based on this observation, values while infants were on steroids and until 72 hours after dexamethasone were excluded from general longitudinal analysis. Pre-dex, on-dex, and off-dex levels of CDIlb, CD18, and CD62L on neutrophils and monocytes were compared.
Evaluation of CD11b, CD 18, and CD62L

Freshly obtained arterial blood was stained to evaluate subpopulations of leucocytes expressing adhesion molecules using FITC and PE labelled monoclonal antibodies against CD11b, CD18, and CD62L (Becton Dickinson) by the standard lyse/wash method. ${ }^{23}$ The population gates were confirmed by a CD45FITC/CD14PE (Becton Dickinson) stain (lymphocytes are CD45bright/CD14negative, monocytes are CD45bright/CD14bright, granulocytes are CD45+/CD14dim). Percent positive cells and molecule density of CDllb, CDl8, and CD62L were measured using Cell Quest software (Becton Dickinson). Percent positive values were standardised using isotype matched irrelevant murine antibodies (Becton Dickinson). Molecule density was estimated using geometric mean of percent positive cells.

\section{Analysis and statistics}

Repeated measures analysis of covariance (RMANCOVA) was used to determine whether a particular outcome variable (CD $1 \mathrm{lb}, \mathrm{CD} 18$, and C62L on neutrophils and monocytes) varied by group (non-BPD versus BPD patients) and whether a group-by-day interaction existed. The repeated measures analysis was adjusted for the covariates gestational age and birth weight. Adjustment for these "confounding" variables was indicated due to their differences across groups (table 1) and correlations with each of the outcome variables. Infants were analysed as non-BPD, BPD 28 days, BPD 36 weeks, and combined BPD. Since both the groups of infants with BPD had chest radiographs consistent with BPD and all the infants in both the groups were oxygen dependent on day 28 , two BPD groups were combined to achieve a bigger sample size and referred to as "combined BPD". No group-by-day interaction was found for any of the six variables for nonBPD infants compared to BPD 28 days, BPD 36 weeks, and combined BPD infants. In the absence of a group-by-day interaction, no separate analysis was performed for each day since lack of interaction indicates that the group effect was uniform across all days. Analysis of residuals suggested that the normality assumptions required for application of RMANCOVA were tenable. An RMANCOVA result was considered significant if $p<0.05$. RMANOVA was used to compare pre-dex, on-dex, and off-dex levels of adhesion markers in the three groups of infants, and also to compare absolute neutrophil and monocyte counts on postnatal days $1,3,7,14,21$, and 28 .

\section{RESULTS}

\section{Characteristics of the study group}

Table 1 gives the characteristics of 40 infants with RDS that completed the study. Infants in the non-BPD group were significantly larger in weight and older in gestational age compared to infants in either clinically defined group of BPD infants, BPD d28, and BPD 36 weeks. Differences were significant for both groups compared with RDS infants who did not develop BPD $(\mathrm{p}<0.001$ for all comparisons $)$. Only $15 \%$ of the non-BPD infants were treated with dexamethasone during the third or fourth week of life compared with $31 \%$ of the BPD d28 infants and 55\% of the BPD 36 weeks infants. The two infants in the non-BPD group of 27 weeks gestational age were treated with dexamethasone for high ventilator settings and oxygen requirements on postnatal day 15-16. Both responded very well and were off oxygen before postnatal day 28. Infection rates were different in the two groups of BPD infants. To reduce or eliminate effects that dexamethasone treatment might have on adhesion molecule expression, data at all time points during which the infants were on dexamethasone treatment and for three days after discontinuation of dexamethasone were excluded from analysis of longitudinal effects. Similarly, all the data points 
Table 1 Characteristics of infants

\begin{tabular}{|c|c|c|c|}
\hline & Non-BPD $(n=13)$ & BPD d28 ( $n=16)$ & BPD 36 weeks $(n=11)$ \\
\hline \multicolumn{4}{|l|}{ Race } \\
\hline White (\%) & 30.8 & 43.8 & 54.5 \\
\hline Black (\%) & 46.2 & 50.0 & 36.4 \\
\hline Asian (\%) & 23.1 & 6.3 & 9.1 \\
\hline Male (\%) & 46.2 & 56.3 & 45.5 \\
\hline Weight $(\mathrm{g})^{*}$ & $1110.9(134.6)$ & $833.8(118.6)$ & 670.9 (64.3) \\
\hline Gestation (weeks)* & $28.8(1.2)$ & $26.0(1.1)$ & $24.9(1.2)$ \\
\hline Apgar $1 \mathrm{~min}^{*}$ & $7(1.3)$ & $6(1.8)$ & $5(1.7) \dagger$ \\
\hline Apgar $5 \mathrm{~min}^{*}$ & $8(0.8)$ & $7(1.4)$ & $7(0.7) \dagger$ \\
\hline Antenatal steroid (\%) & 76.9 & 68.8 & 63.6 \\
\hline Caesarean section (\%) & 46.15 & 50.0 & $72.7 \dagger$ \\
\hline No. of ventilation days ${ }^{*}$ & $2.9(3.9)$ & $13.1(10.5)$ & $41.2(28.7)$ \\
\hline No. of days on oxygen* & $13(10.0)$ & $45.9(15.7)$ & $94.8(2.06)$ \\
\hline Length of hospital stay* & $49.9(11.1)$ & $75.8(13.2)$ & $118.2(16.6)$ \\
\hline $\begin{array}{l}\text { Postnatal steroid (\%) } \\
\text { (during 3rd or } 4 \text { th week) }\end{array}$ & 15.4 & 31 & 55 \\
\hline $\begin{array}{l}\text { Blood culture positive (\%) } \\
\text { (during 3rd or } 4 \text { th week) }\end{array}$ & 0 & 25.0 & 45.5 \\
\hline \multicolumn{4}{|c|}{$\begin{array}{l}\text { *Values are mean (SD). } \\
p \text { values for non-BPD versus BPD d } 28 \text { and BPD } 36 \text { weeks for variables including birth weight, gestational age, } \\
\text { number of ventilation days, number of days on oxygen, length of NICU stay, postnatal dexamethasone and blood } \\
\text { culture positive are }<0.01 \text { each. } \\
\text { †Represents } p<0.01 \text { for BPD } 36 \text { weeks versus non-BPD. }\end{array}$} \\
\hline
\end{tabular}

during the time of positive blood culture and until a negative culture was obtained, were not included. No infant was culture positive or received dexamethasone during the first two weeks of the study, so no data from this period was affected. The number of blood samples analysed on days 1, 3, 7 , and 14 was very close to the number of patients in each group (a range of $11-13,13-16$, and 10-11 in non-BPD, BPD $\mathrm{d} 28$, and BPD 36 weeks infants respectively); and on day 21 and 28, number of samples were in the range 11-12, 13-15, and $7-10$ in non-BPD, BPD d28, and BPD 36 weeks infants respectively.

Longitudinal changes in adhesion marker expression When the relative percentages of neutrophils and monocytes positive for adhesion markers, CDllb, CDl8, and CD62L, were examined among the study groups over the period of the study no differences were found. Percentage of neutrophils expressing CDllb, CD18, and CD62L on all the postnatal days was similar among the three groups. (Mean (range): CDllb: 97.8\% (94.28-99.5\%), CD18: 97.01\% (93.298.42\%), CD62L: $90.35 \%(64.5-99.98 \%))$. Percentage of monocytes expressing CD11b, CD18, and CD62L on all the postnatal days was also similar among the three groups (mean (range): CDllb: 93.7\% (78.79-96.43\%), CDl8: 94.5\% (82.47-96.59\%), CD62L: 86.08\% (73.76-97.38\%)). Further, there was no significant change over time in these levels in the three study groups.

Figures 1-3 depict mean fluorescence intensity (unadjusted data) of surface adhesion molecules, CDl8, CDllb, and CD62L on neutrophils and CD18 on monocytes in nonBPD, BPD d28, and BPD 36 weeks infants. Analysis was not performed for unadjusted data because adjusted means were very close to unadjusted means.

Table 2 shows adhesion marker expression when infants with BPD d28 and BPD 36 weeks were combined into a single group (combined BPD) and mean fluorescence intensities were adjusted for birth weight and gestational age (RMANCOVA used). Data are shown as mean, standard error and 95\% confidence interval limits. Table 3 shows p values for the separate comparisons of non-BPD infants with BPD d28, BPD 36 weeks, and combined BPD infants. CD18 expression on neutrophils and monocytes was significantly decreased in combined BPD infants compared to non-BPD infants on all days $(\mathrm{p}<0.044, \mathrm{p}<0.042$ respectively). Analysis for CD62L expression on neutrophils, but not on monocytes also showed a significant decrease in combined BPD infants compared to non-BPD infants $(\mathrm{p}<0.028)$. Separate comparisons of non-BPD infants with BPD d28 and BPD 36 weeks were significant for CD18 on monocytes (both $\mathrm{p}<0.05$ ), but not for CD18 on neutrophils or CD62L on neutrophils and monocytes. CDllb on monocytes, but not on neutrophils was decreased in BPD 36 weeks and BPD d 28 infants compared to non-BPD infants $(p<0.05)$. However, comparison of this variable between combined BPD and non-BPD infants was not statistically significant. Change of adhesion molecules with postnatal age was noticed only for monocytes for all the three markers, but not for neutrophils. CDl8, CDllb, and CD62L on monocytes changed with postnatal age significantly $(p<0.01)$ but direction of change varied at different postnatal days as shown in table 2 .

\section{Absolute neutrophil and monocyte counts}

In non-BPD infants, absolute neutrophil count (ANC) remained in the range 2820 (1006) to 5213 (3089) per $\mathrm{mm}^{3}$ (mean (SD)) over the first four weeks of life. However, in the BPD d28 and BPD 36 weeks infants, ANC increased with postnatal age, peaking on day 14 and decreasing thereafter. Similarly, absolute monocyte counts (AMC) were within the range 1666 (626) to 1901 (1694) per $\mathrm{mm}^{3}$ (mean (SD)) in the non-BPD group, increasing postnatally in the BPD d28 and BPD 36 weeks infants, peaking on day 14 and decreasing thereafter. The differences in ANC and AMC between nonBPD and the two BPD group of infants were significant (RMANOVA, $\mathrm{p}<0.01$; see fig 4 ).

\section{Effect of dexamethasone treatment}

We then assessed the effect of dexamethasone treatment on adhesion molecule expression. Figure 5 shows mean fluorescence for CD11b, CD18, and CD62L on neutrophils and monocytes, before (pre-dex), after 48-72 hours of initiation (on-dex), and after discontinuing steroid (off-dex). Dexamethasone treatment significantly decreased CDllb, CD18, and CD62L expression on neutrophils $(p<0.001$, $\mathrm{p}<0.0003$, and $\mathrm{p}<0.0033$, respectively; RMANOVA), and $\mathrm{CD} 1 \mathrm{lb}$ and $\mathrm{CD} 18$ expression, but not CD62L on monocytes $(\mathrm{p}<0.0008$ and $\mathrm{p}<0.013$ respectively; RMANOVA). Moreover, pairwise comparison between pre-dex and on-dex levels as well as on-dex and off-dex levels for neutrophils CDllb, 

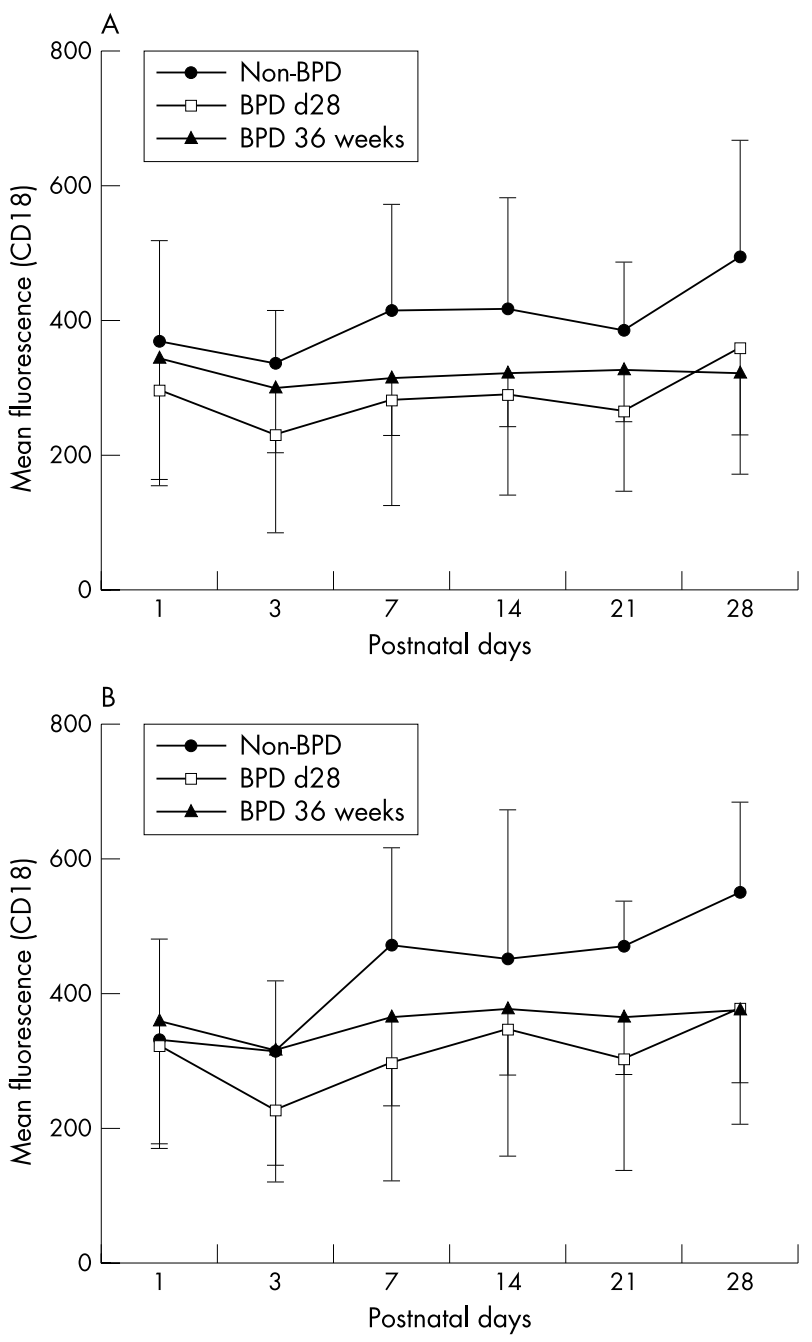

Figure 1 (A) Mean fluorescence intensity (unadjusted data) for CD 18 on neutrophils in non-BPD, BPD d28, and BPD 36 weeks infants. Data are mean (SD). Expression of CD18 was not significantly different in BPD d28 and BPD 36 weeks infants compared to non-BPD infants, but the comparison was significant when the two BPD groups were combined into a single group (combined BPD), and compared with non-BPD $(p<0.044$, RMANCOVA). (B) Mean fluorescence intensity (unadjusted data) for CD18 on monocytes in non-BPD, BPD d28, and BPD 36 weeks infants. Data are given as mean (SD). Expression of CD18 was significantly decreased in BPD d28 and BPD 36 weeks infants compared to non-BPD infants ( $p<0.05$ each, RMANCOVA).

CD18, CD62L, and monocytes CD11b, CD18 were significant $(p<0.05$, Mann-Whitney U test). All of these values normalised after completion of dexamethasone treatment. There were no significant differences between pre- and offdexamethasone values.

\section{DISCUSSION}

Previous studies have suggested that changes in soluble adhesion molecules in serum and tracheal aspirates may characterise the infant with RDS who develops BPD. ${ }^{14}{ }^{18}$ This is the first longitudinal study to examine change in the expression of adhesion molecules on circulating neutrophils and monocytes in the premature neonates with RDS who developed BPD compared with those who did not. Our premise was that changes in the expression of $\mathrm{CDIlb} / \mathrm{CD} 18$ and CD62L on circulating neutrophils and monocytes would reflect and perhaps predict the development of BPD in neonates with RDS, independent of sepsis.

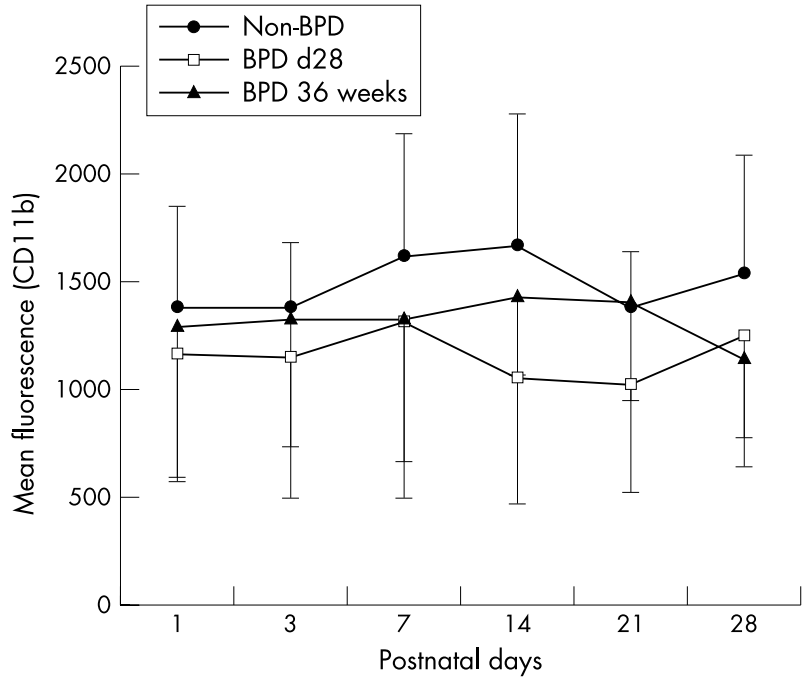

Figure 2 Mean fluorescence intensity (unadjusted data) for $C D 11 \mathrm{~b}$ on neutrophils in non-BPD, BPD d28, and BPD 36 weeks infants. Data are mean (SD). Expression of CD1 $1 \mathrm{~b}$ was not significantly different among non-BPD, BPD d28, and BPD 36 weeks infants.

The definition of BPD continues to be controversial. BPD has been defined as supplemental oxygen beyond 28 days with radiological abnormalities ${ }^{24}$ and also as oxygen dependency at 36 weeks corrected gestational age. ${ }^{25}$ Therefore we evaluated changes in adhesion molecule expression in infants with RDS grouped clinically according to postnatal oxygen dependency with radiographic confirmation. Although there were several confounding variables between the non-BPD and BPD groups of infants, we chose to adjust only for two major variables, gestational age and birth weight, but not for Apgar score, length of hospital stay, or other characteristics. $\mathrm{BPD}$ is almost exclusively seen in preterm infants of less than $1200 \mathrm{~g},{ }^{5}$ and has not been related directly with low Apgar score, length of hospital stay, or duration of ventilation in the absence of prematurity.

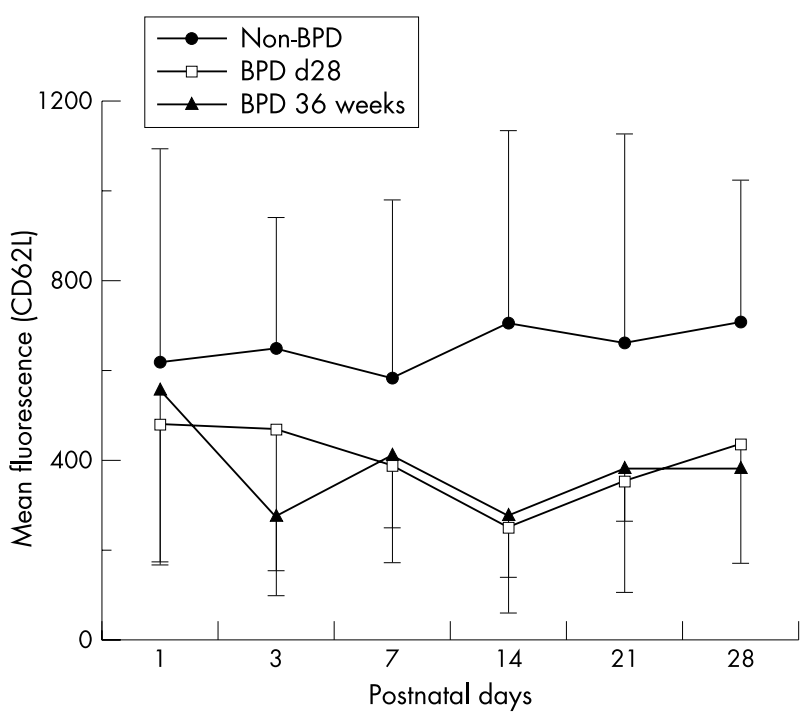

Figure 3 Mean fluorescence intensity (unadjusted data) for CD62L on neutrophils in non-BPD, BPD d28, and BPD 36 weeks infants. Data are mean (SD). Expression of CD62L was not significantly different in BPD d28 and BPD 36 weeks infants compared to non-BPD infants, but the comparison was significant when the two BPD groups were combined into a single group (combined BPD), and compared with non-BPD $(p<0.028$, RMANCOVA used). 
Table 2 Adjusted mean fluorescence intensities for CD18, CD1 1b, and CD82L on neutrophils and monocytes in non-BPD and combined BPD infants (BPD) (adjustment made for birth weight and gestational age)

\begin{tabular}{|c|c|c|c|c|c|c|}
\hline \multirow[b]{2}{*}{ Groups } & \multicolumn{6}{|l|}{ Postnatal days } \\
\hline & 1 & 3 & 7 & 14 & 21 & 28 \\
\hline \multicolumn{7}{|c|}{ CD18 on neutrophils } \\
\hline Non-BPD & $\begin{array}{l}361(51) \\
(258 \text { to } 464)\end{array}$ & $\begin{array}{l}381(52) \\
(278 \text { to } 485)\end{array}$ & $\begin{array}{l}420(49) \\
(323 \text { to } 517)\end{array}$ & $\begin{array}{l}417(50) \\
(318 \text { to } 516)\end{array}$ & $\begin{array}{l}420(53) \\
\text { (314 to } 527)\end{array}$ & $\begin{array}{l}459(52) \\
(355 \text { to } 562)\end{array}$ \\
\hline BPD & $\begin{array}{l}313(32) \\
(249 \text { to } 377)\end{array}$ & $\begin{array}{l}246 \text { (39) } \\
(168 \text { to } 324)\end{array}$ & $\begin{array}{l}283(32) \\
(218 \text { to } 348)\end{array}$ & $\begin{array}{l}299(33) \\
(233 \text { to } 366)\end{array}$ & $\begin{array}{l}291(30) \\
(230 \text { to } 352)\end{array}$ & $\begin{array}{l}319(34) \\
(251 \text { to } 387)\end{array}$ \\
\hline \multicolumn{7}{|c|}{ CD18 on monocytes } \\
\hline Non-BPD & $\begin{array}{l}350(57) \\
(236 \text { to } 464)\end{array}$ & $\begin{array}{l}364(57) \\
(249 \text { to } 479)\end{array}$ & $\begin{array}{l}482(54) \\
(375 \text { to } 590)\end{array}$ & $\begin{array}{l}464(54) \\
\text { (358 to } 572)\end{array}$ & $\begin{array}{l}504(61) \\
(382 \text { to } 626)\end{array}$ & $\begin{array}{l}579(57) \\
(465 \text { to } 694)\end{array}$ \\
\hline BPD & $\begin{array}{l}332(36) \\
(261 \text { to } 404)\end{array}$ & $\begin{array}{l}274(45) \\
(184 \text { to } 364)\end{array}$ & $\begin{array}{l}315(36) \\
(244 \text { to } 387)\end{array}$ & $\begin{array}{l}361(38) \\
(286 \text { to } 437)\end{array}$ & $\begin{array}{l}334(34) \\
(267 \text { to } 401)\end{array}$ & $\begin{array}{l}368(36) \\
(297 \text { to } 440)\end{array}$ \\
\hline \multicolumn{7}{|c|}{ CDII on neutrophils } \\
\hline Non-BPD & $\begin{array}{l}1375(207) \\
(962 \text { to } 1788)\end{array}$ & $\begin{array}{l}1492(208) \\
(1076 \text { to } 1908)\end{array}$ & $\begin{array}{l}1676(193) \\
\text { (1290 to } 2062)\end{array}$ & $\begin{array}{l}1719(193) \\
(1333 \text { to } 2105)\end{array}$ & $\begin{array}{l}1556(214) \\
(1126 \text { to } 1985)\end{array}$ & $\begin{array}{l}1628(201) \\
(1226 \text { to } 2031)\end{array}$ \\
\hline BPD & $1219(136)$ & $1164(171)$ & $1273(133)$ & $1168(141)$ & 1154 (129) & $1138(140)$ \\
\hline \multicolumn{7}{|c|}{ CDIl on monocytes } \\
\hline Non-BPD & $\begin{array}{l}886(173) \\
(539 \text { to } 1233)\end{array}$ & $\begin{array}{l}1016(175) \\
(667 \text { to } 1365)\end{array}$ & $\begin{array}{l}1273(164) \\
(945 \text { to } 1601)\end{array}$ & $\begin{array}{l}1262(164) \\
(934 \text { to } 1590)\end{array}$ & $\begin{array}{l}1213(179) \\
\text { (854 to } 1572 \text { ) }\end{array}$ & $\begin{array}{l}1338 \text { (167) } \\
\text { (1005 to } 1672)\end{array}$ \\
\hline BPD & $\begin{array}{l}884(109) \\
(665 \text { to } 1102)\end{array}$ & $\begin{array}{l}777(129) \\
(520 \text { to } 1034)\end{array}$ & $\begin{array}{l}935(109) \\
(717 \text { to } 1154)\end{array}$ & $\begin{array}{l}908(113) \\
(682 \text { to } 1135)\end{array}$ & $\begin{array}{l}890(104) \\
(682 \text { to } 1099)\end{array}$ & $\begin{array}{l}1042(108) \\
(825 \text { to } 1259)\end{array}$ \\
\hline \multicolumn{7}{|c|}{ CD62L on neutrophils } \\
\hline Non-BPD & $\begin{array}{l}719(118) \\
(484 \text { to } 954)\end{array}$ & $\begin{array}{l}581(118) \\
(345 \text { to } 817)\end{array}$ & $\begin{array}{l}614(113) \\
(388 \text { to } 840)\end{array}$ & $\begin{array}{l}740(113) \\
(514 \text { to } 966)\end{array}$ & $\begin{array}{l}617(120) \\
(376 \text { to } 858)\end{array}$ & $\begin{array}{l}710(114) \\
\text { (481 to } 938)\end{array}$ \\
\hline BPD & $\begin{array}{l}474(75) \\
(324 \text { to } 623)\end{array}$ & $\begin{array}{l}293(85) \\
(124 \text { to } 462)\end{array}$ & $\begin{array}{l}353(77) \\
(200 \text { to } 507)\end{array}$ & $\begin{array}{l}241(79) \\
(84 \text { to } 399)\end{array}$ & $\begin{array}{l}307 \text { (73) } \\
(161 \text { to } 453)\end{array}$ & $\begin{array}{l}364(75) \\
(215 \text { to } 514)\end{array}$ \\
\hline \multicolumn{7}{|c|}{ CD62L on monocytes } \\
\hline Non-BPD & $\begin{array}{l}490(87) \\
\text { (316 to 664) }\end{array}$ & $\begin{array}{l}314 \text { (88) } \\
\text { (139 to } 490)\end{array}$ & $\begin{array}{l}353(84) \\
(186 \text { to } 520)\end{array}$ & $\begin{array}{l}320(84) \\
\text { (153 to } 487)\end{array}$ & $\begin{array}{l}246(90) \\
(67 \text { to } 425)\end{array}$ & $\begin{array}{l}392(85) \\
(222 \text { to } 561)\end{array}$ \\
\hline BPD & $\begin{array}{l}378(55) \\
(268 \text { to } 488)\end{array}$ & $\begin{array}{l}307(65) \\
\text { (177 to } 437)\end{array}$ & $\begin{array}{l}268(55) \\
(159 \text { to } 378)\end{array}$ & $\begin{array}{l}225(55) \\
(115 \text { to } 334)\end{array}$ & $\begin{array}{l}261(53) \\
(155 \text { to } 367)\end{array}$ & $\begin{array}{l}272(55) \\
(162 \text { to } 381)\end{array}$ \\
\hline
\end{tabular}

Combined BPD: both BPD d28 and BPD 36 weeks infants put together.

Data are adjusted mean (SE) error, with $95 \% \mathrm{Cl}$ underneath.

Before and after adjustment for birth weight and gestational age, we observed decreased CD18 expression on neutrophils and monocytes, and decreased CD62L expression on neutrophils during the first four weeks of postnatal life in infants who developed BPD. Dexamethasone use was associated with even greater decreased expression of CD11b, CD18, and CD62L.

During inflammation, neutrophil diapedesis is observed in a wide range of settings. Rolling attachment of neutrophils to endothelium is mediated by CD62L and can be blocked by

Table 3 p values for the comparison of non-BPD with BPD d28, BPD 36 weeks, and combined BPD

(RMANCOVA used, adjustment for the covariates birth weight and gestational age)

\begin{tabular}{|c|c|c|c|}
\hline Variables & $\begin{array}{l}\text { Non-BPD v BPD } \\
\text { d28 }\end{array}$ & $\begin{array}{l}\text { Non-BPD v BPD } \\
36 \text { weeks }\end{array}$ & $\begin{array}{l}\text { Non-BPD } v \text { combined } \\
\text { BPD }\end{array}$ \\
\hline \multicolumn{4}{|l|}{ CD18 } \\
\hline $\begin{array}{l}\text { Neutrophils } \\
\text { CD18 }\end{array}$ & NS & NS & $<0.044$ \\
\hline $\begin{array}{l}\text { Monocytes } \\
\text { CD1 lb }\end{array}$ & $<0.05$ & $<0.05$ & $<0.042$ \\
\hline $\begin{array}{l}\text { Neutrophils } \\
\text { CD11b }\end{array}$ & NS & NS & NS \\
\hline $\begin{array}{l}\text { Monocytes } \\
\text { CD62L }\end{array}$ & $<0.04$ & $<0.04$ & NS \\
\hline $\begin{array}{l}\text { Neutrophils } \\
\text { CD62L }\end{array}$ & NS & NS & $<0.028$ \\
\hline Monocytes & NS & NS & NS \\
\hline
\end{tabular}

Since there was no group-by-day interaction for any of these variables, the $p$ values apply to all days including day $1,3,7,14,21$, and 28 for the comparison of non-BPD with BPD d28, BPD 36 weeks, and combined BPD infants.

NS, not significant. antibodies against CD62L, and firm adherence is mediated by $\mathrm{CD} 18 .^{26} \mathrm{CD} 1 \mathrm{lb} / \mathrm{CD} 18$ have emerged as a critical molecule in neutrophil dependent inflammation. ${ }^{27}{ }^{28}$ Previous studies have suggested that infants who develop BPD show signs of fetal inflammatory response detectable as IL-6 in cord blood $^{6}$ and as an increase in expression of CDllb on neutrophils compared with healthy preterm infants. ${ }^{11}$ The pulmonary increase in neutrophils occurs transiently in RDS and becomes persistent in BPD. Markers of inflammation such as ICAM-1 and IL- 8 are increased in bronchial lavage fluid in infants who subsequently develop BPD, and correlation with pulmonary neutrophilia has been reported. ${ }^{29}$ An increase in inflammatory cytokines, IL-1 $\beta$, IL-6, and IL-8 precedes the influx of neutrophils found in tracheal aspirates in infants who develop BPD. ${ }^{30}$ In addition, increases in soluble E-selectin and ICAM-1 in serum, and L-selectin in tracheal aspirates appear to be associated with the development of BPD. ${ }^{14}{ }^{18}$ In one study ${ }^{18}$ CD1lb/CD18 expression on neutrophils in bronchoalveolar lavage fluid increased over the first 17 days of life in BPD infants. Thus, inflammation is important to the aetiology of BPD. Both IL-6 and CD18/ CDllb expression are increased in sepsis in the premature infant. ${ }^{31}$ Neonatal neutrophil deficiencies are considered a key factor in neonatal susceptibility to bacterial infection ${ }^{32}$ and to affect diapedesis. CDl lb/CD18 expression on neonatal neutrophils has been reported as similar to or even increased compared with adults and is not affected by gestational age. ${ }^{33}$ This controversy has been resolved by Reddy and colleagues, ${ }^{34}$ who observed that neonatal cord blood was comprised of a mixed population of immature neutrophils with reduced $\beta_{2}$ integrin expression and mature neutrophils with normal adult levels. Immaturity was associated with younger gestational age and reduced respiratory burst function.

The finding that CD18 was decreased in BPD infants, whereas CDllb was not significantly decreased in BPD 

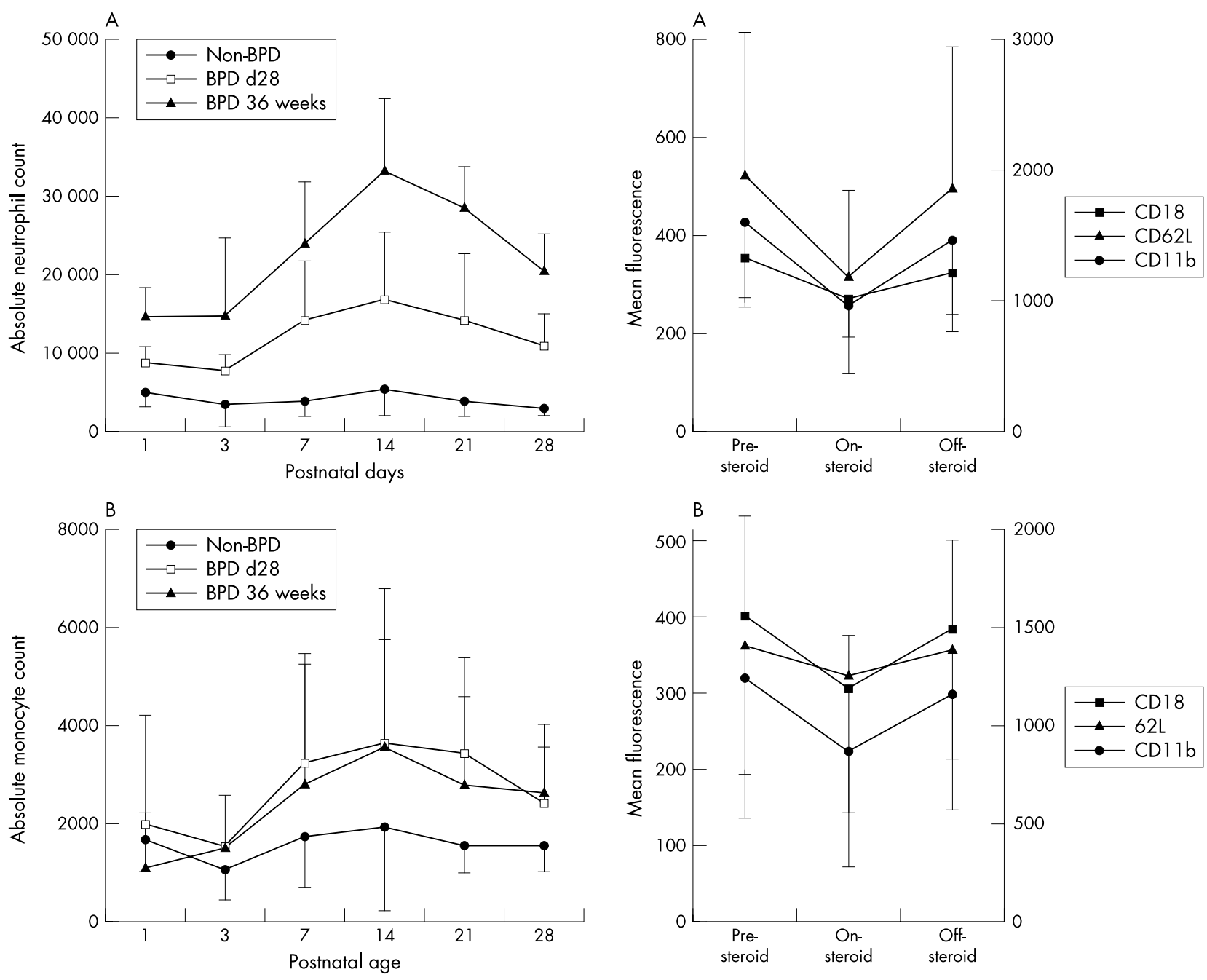

Figure 4 (A) Absolute neutrophil count in non-BPD, BPD d28, and BPD 36 weeks infants. Data are mean (SD). In non-BPD infants, absolute neutrophil count (ANC) did not change with postnatal age significantly over the first four weeks of life. However, in the two BPD groups of infants, ANC increased with postnatal age, peaking on day 14 and then decreased thereafter. The ANC was significantly increased in BPD d28 and BPD 36 weeks infants compared to non-BPD infants (RMANOVA, $\mathrm{p}<0.01$ each). (B) Absolute monocyte count in non-BPD, BPD d28, and BPD 36 weeks infants. Data are mean (SD). In non-BPD infants, absolute monocyte count (AMC) did not change significantly over the first four weeks of life. However, in the two BPD groups of infants, AMC increased with postnatal age, peaking on day 14 and then decreased thereafter. The AMC was significantly increased in BPD d28 and BPD 36 weeks infants compared to non-BPD infants (RMANOVA, $p<0.01$ each).

infants compared to non-BPD infants is intriguing. This difference may be related to the fact that expression of CDIlb on neutrophils did not increase after day 3 in the non-BPD infants, whereas this trend was observed for CD18 (fig 1). CDIlb is very densely expressed on neutrophils, and forms a heterodimer with CD18, but these are separate chains.

Absolute neutrophil counts were significantly higher in BPD infants compared to non-BPD infants consistent with the previous observations in the first five days of life. ${ }^{35}$ However, there was no simple relationship between the increasing ANC and AMC in BPD infants over the course of study and decreased surface adhesion molecules (CD18 and CD62L), which might reflect alteration in haematopoiesis or production of immature cells.

We measured serial levels of CD11b, CD18, and CD62L expression on neutrophils and monocytes in blood between

Figure 5 (A) Effect of corticosteroid treatment expression of CD1 1b, CD18, and CD62L on neutrophils. Data are mean (SD). Expression of CD1 1b, CD18, and CD62L on neutrophils decreased after initiation of steroid ( $p<0.001$ for all three, RMANOVA). Y-axis (left) represents axis for $C D 18$ and $C D 62 L$ and $Y-1$ axis (right) represents axis for CD1 $1 \mathrm{~b}$ on neutrophils. (B) Effect of corticosteroid treatment expression of CD1 1b, CD18, and CD62L on monocytes. Data are mean (SD). Expression of $C D 11 b$ and $C D 18$ on monocytes decreased $(p<0.001$ and $p<0.05$ respectively, RMANOVA). The effect was not significant for CD62L on monocytes. Y-axis (left) represents axis for CD18 and CD62L and Y-1 axis (right) represents axis for $\mathrm{CD} 1 \mathrm{lb}$ on monocytes.

BPD and non-BPD infants to look for the critical relationships. In related studies, we found that low soluble L-selectin was associated with the development of BPD. ${ }^{36}$ Here we report that CD18 expression on neutrophils and monocytes is significantly decreased in BPD neonates compared to nonBPD neonates on day 1 to day 28. This is the first report of reduced expression of $\beta_{2}$ integrin in association with the development of BPD. Low CD18 may reflect the development of BPD in the infant with RDS for at least two reasons. First this may reflect greater shedding of these molecules in response to inflammation or to stress. Recent studies suggest that stress may reduce CD18 expression and that the circulating neutrophil is not the same as the neutrophil responding to inflammation. ${ }^{37}$ Oxidative stress is characteristic in premature infants and is worsened by reduced antioxidant capacity. ${ }^{38}$ We speculate that reduced CD18 and CD62L expression may reflect this and that neutrophils with reduced CD18 expression would be preferentially retained in circulating blood, while neutrophils with normal or increased 
expression might be more likely both to migrate and to be detained in the bronchi and lungs. This interpretation is indirectly supported by the studies of Kotecha et al, who found increased expression of CDIlb/CDI8 in lavage fluid over the first 17 days of life in infants who developed BPD. Secondly, these findings may reflect the existence of a mixed population of mature and immature neutrophils in premature infants as reported by Reddy and colleagues, ${ }^{34}$ which should be correspondingly greater in infants of younger gestational age. Here correction for birth weight and gestational age did not eliminate the differences between non-BPD and BPD, and so this is modulated by factors other than these.

In the present study, reduction of adhesion molecules during steroid treatment was seen in both non-BPD and BPD babies. The decrease in CD62L after starting dexamethasone has been reported previously in BPD neonates and healthy adults. ${ }^{20}$ The reduction in mean fluorescence of CD18 after dexamethasone has been shown in cows, but not previously in humans. ${ }^{39}$ We observed that the expression of CD18 on neutrophils and monocytes, and CD62L on neutrophils, was decreased in BPD infants and that dexamethasone treatment further decreased these levels. Thus dexamethasone is likely to reduce leucocyte count and extravasation, which happens when $\mathrm{CD} 1 \mathrm{lb} / \mathrm{CD} 18$ expression is impaired experimentally. Conversely, administration of recombinant human granulocyte stimulating factor in neonatal sepsis causes increased expression of $\beta_{2}$ integrin in addition to increasing neutrophil number. ${ }^{40}$ Recent studies suggest that an important function of $\beta_{2}$ integrin adhesion is induction of intracellular signal transduction in adherent cells, leading to neutrophil cytokine production. ${ }^{41}$ This signal transduction pathway involves CD11b/CD18 recruitment of a Toll/Il-1 receptor family cascade to modulate NF- $\kappa \mathrm{B}^{42}$ Reduced expression of $\mathrm{CD} 1 \mathrm{lb} / \mathrm{CD} 18$ during dexamethasone treatment should dampen this response. The implications of reduced CD1lb/CD18 expression on the inflammatory process in BPD appear to be significant and warrant further investigation.

\section{Authors' affiliations}

P Ballabh, A N Krauss, A Jain, Division of Neonatology, New York Presbyterian Hospital, Weill Medical College of Cornell University, New York, USA

M Simm, C Califano, S Cunningham-Rundles, Division of Hematology/ Oncology/Immunology, New York Presbyterian Hospital, Weill Medical College of Cornell University, New York, USA

M L Lesser, Biostatistics Unit North Shore and LIJ Research Institute, New York, USA

Presented at meeting of the Society of Pediatric Research 2001, Baltimore, on 29 April 2001

Supported by NIH RR06020

\section{REFERENCES}

1 Martin RJ, Walsh-Sukys MC. Bronchopulmonary dysplasia-no simple solution. N Engl J Med 1999;340:1005-10.

$2 \mathrm{Ng}$ DK, Lau WY, Lee SL. Pulmonary sequelae in long-term survivors of bronchopulmonary dysplasia. Pediatr Int 2000;42:603.

3 Bancalari $E$. Changes in pathogenesis and prevention of chronic lung disease of prematurity. Am J Perinatol 2001;18:1-9.

4 Speer CP. New insights into the pathogenesis of pulmonary inflammation in preterm infants. Biol Neonate $2001 ; 79: 205-9$.

5 Jobe AH, Akegami M. Prevention of bronchopulmonary dysplasia. Curr Opin Pediatr 2001; 13:124-9.

6 Yoon BH, Romero R, Kim KS, et al. A systemic fetal inflammatory response and the development of bronchopulmonary dysplasia. Am J Obstet Gynecol 1999;181:773-9

7 Bhuta T, Ohlsson A. Systemic review and meta-analysis of early postnatal dexamethasone for prevention of chronic lung disease. Arch Dis Child Fetal Neonatal Ed 1998;79:F26-33.
8 Cole $\mathrm{CH}$, Colton $\mathrm{T}$, Shah $\mathrm{BL}$, et al. Early inhaled glucocorticoid therapy to prevent bronchopulmonary dysplasia. N Engl J Med 1999;340:1005-10.

9 Shah V, Ohlsson A. Postnatal dexamethasone in prevention of chronic lung disease. In: David TJ, ed. Recent advances in pediatrics 19. London: Churchill Livingston, 2001:77-96.

10 Barrington KJ. Postnatal steroids and neurodevelopmental outcomes: a problem in the making. Pediatrics 2001;107:1425-6.

11 Sarafidis K, Drossou-Agakidou V, Kanakoudi-Tsakalidou F, et al. Evidence of early systemic activation and transendothelial migration of neutrophils in neonates with severe respiratory distress syndrome. Pediatr Pulmonol 2001;31:214-19.

12 Homeister JW, Zhang M, Frenette PS, et al. Overlapping functions of E- and P-selectin in neutrophil recruitment during acute inflammation. Blood 1998;92:2345-52.

13 Tedder TF, Steeber DA, Pizcueta P. L-selectin-deficient mice have impaired leukocyte recruitment into inflammatory sites. J Exp Med 1995;181:2259-64.

14 Ramsay PL, O'Brian Smith E, Hegemier S, et al. Early clinical markers for the development of bronchopulmonary dysplasia: soluble E-selectin and ICAM-1. Pediatrics 1998; 102:927-32.

15 Rogowski O, Sasson Y, Kassirer M, et al. S Down-regulation of the CD62L antigen as a possible mechanism for neutrophilia during inflammation. Br J Haematol 1998; 101:666-9

16 Eriksson EE, Xie X, Werr J, et al. Importance of primary capture and L-selectindependent secondary capture in leukocyte accumulation in inflammation and atherosclerosis in vivo. J Exp Med 2001;194:205-18.

17 Weirich E, Rabin RL, Maldonado Y, et al. Neutrophil CD 11 b expression as diagnostic marker for early-onset neonatal infection. J Pediatr 1998:132:445-51.

18 Kotecha S, Silverman M, Shaw RJ, et al. Soluble L-selectin in bronchoalveolar lavage fluid obtained from infants who develop chronic lung disease of prematurity. Arch Dis Child Fetal Neonatal Ed 1998;78:F143-7.

19 Filep JG, Delalandre A, Payette Y, et al. Glucocorticoid receptor regulates expression of L-selectin and CD1 1b/CD1 8 on human neutrophils. Circulation 1997;96:295-301.

20 Waisman D, Van Eeden SF, Hogg JC, et al. L-selectin expression on polymorphonuclear leukocytes and monocytes in premature infant: reduced expression after dexamethasone treatment for bronchopulmonary dysplasia. J Pediatr 1998;132:53-6

21 Rezzonico R, Imbert V, Chicheportiche R, et al. Ligation of $C D 11 \mathrm{~b}$ and $C D 11 \mathrm{c}$ beta(2) integrins by antibodies or soluble CD23 induces macrophage inflammatory protein lalpha (MIP-1alpha) and MIP-1 beta production in primary human monocytes through a pathway dependent on nuclear factorkappa B. Blood 2001;97:2932-40.

22 Northway WH, Rosen RC, Porter DY. Pulmonary disease following respiratory therapy of hyaline membrane disease. Bronchopulmonary dysplasia. N Engl J Med 1967;276:357-68.

23 Paxton H, Cunningham-Rundles S, O'Gorman. MRG Laboratory evaluation of the cellular immune system. In: Henry JB, ed. Clinical diagnosis and management by laboratory methods. W.B. Saunders and Co, 2001:850-77.

24 Bancalari E, Abdenour GE, Feller R, et al. Bronchopulmonary dysplasia: clinical presentation. J Pediatr 1979;95:819-23.

25 Shennan AT, Dunn MS, Ohlsson A, et al. Abnormal pulmonary outcomes in premature infants. Pediatrics 1988;82:527-32.

26 Spertini O, Luscinskas FW, Munro JM, et al. Leukocyte adhesion molecule-1 (LAM-1, L-selectin) interacts with an inducible endothelial cell ligand to support leukocyte adhesion. J Immunol 1991;147:2565-73.

27 Luscinskas FW, Kiely JM, Ding H, et al. In vitro inhibitory effect of IL-8 and other chemoattractants on neutrophil-endothelial adhesive interactions. J Immunol 1992;149:2163-71.

28 Malik AR, Lo SK. Vascular endothelial adhesion molecules and tissue inflammation. Pharmacol Rev 1996;48:213-29.

29 Little S, Dean T, Bevin S, et al. Role of elevated plasma soluble ICAM-1 and bronchial lavage fluid IL-8 levels as markers of chronic lung disease in premature infants. Thorax 1995;50:1073-9.

30 Kotecha S, Wilson L, Wangoo A, et al. Increase in interleukin (IL)-1 beta and IL- 6 in bronchoalveolar lavage fluid obtained from infants with chronic lung disease of prematurity. Pediatr Res 1996;40:250-6.

$31 \mathrm{Ng} \mathrm{PC}$, Cheng SH, Chui KM, et al. Diagnosis of late onset neonatal sepsis with cytokines, adhesion molecule, and C-reactive protein in preterm very low birthweight infants. Arch Dis Child Fetal Neonatal Ed 1997;77:F221-7.

32 Cunningham-Rundles S, Nesin M. Bacterial infections. In: Nataro JP, Blaser MJ, Cunningham-Rundles S, eds. The immunologically compromised host in 2000. Persistent bacterial infections. Washington, DC: American Society of Microbiology Press, 2000: 145-64.

33 McEvoy LT, Zakem-Cloud H, Tosi MF. Total cell content of CR3 (CD1 1b/ CD18) and LFA-1 (CD1 1a/CD18) in neonatal neutrophils: relationship to gestational age. Blood 1996;87:3929-3.

34 Reddy RK, Xia Y, Hanikyrova M, et al. A mixed population of immature and mature leucocytes in umbilical cord blood results in a reduced expression and function of CR3 (CD1 1b/CD18). Clin Exp Immunol 1998;1 14:462-7.

35 Kohelet D, Arbel E, Ballin A, et al. Variations in neutrophil count in preterm infants with respiratory distress syndrome who subsequently developed chronic lung disease. Am J Perinatol 2000;17:159-62.

36 Ballabh P, Kumari J, Shin J, et al. Soluble E-selectin, soluble L-selectin and soluble ICAM- 1 in bronchopulmonary dysplasia and changes with corticosteroid. Pediatr Res 2001;49:1643A.

37 Sasson Y, Zeltser D, Rogowski O, et al. Neutrophilia of infection/ inflammation: are we really dealing with "inflamed" leukocytes? J Med 1998;29:217-29. 
38 Rogers S, Witz G, Anwar M, et al. Antioxidant capacity and oxygen radical diseases in the preterm newborn. Arch Pediatr Adolesc Med 2000;154:544-8.

39 Burton JL, Kehrli ME. Regulation of neutrophil adhesion molecules and shedding of Staphylococcus aureus in milk of cortisol and dexamethasonetreated cows. Am J Vet Res 1995;56:997-1006.

40 Drossou-Agakidou V, Kanakoudi-Tsakalidou F, Sarafidis K, et al. Administration of recombinant human granulocyte-colony stimulating factor to septic neonates induces neutrophilia and enhances the neutrophil respiratory burst and beta 2 integrin expression. Results of a randomized controlled trial. Eur J Pediatr 1998;157:583-8.

41 Walzog B, Weinmann P, Jeblonski F, et al. A role for beta(2) integrins (CDI 1/ $\mathrm{CD} 18$ ) in the regulation of cytokine gene expression of polymorphonuclear neutrophils during the inflammatory response. FASEB J 1999;13:1855-65.

42 Shi C, Zhang X, Chen Z, et al. Leukocyte integrin mac-1 recruits toll/ interleukin-1 receptor superfamily signaling intermediates to modulate NFkappaB activity [In Process Citation]. Circ Res 2001;89:859-65.

\section{CORRECTION}

Please note that there is an error in the author list for the article by Burgess et al (Consent for clinical research in the neonatal intensive care unit: a retrospective survey and a prospective study Arch Dis Child Fetal Neonatal Ed 2003;88:F280-F286) shown on the FNN July online table of contents (www.archdischild.com). The correct list is shown here:

E Burgess, N Singhal, H Amin, D D McMillan, H Devrome

AC Fenton is the author of the commentary which accompanies this article. The error is much regretted. 